\title{
MÍDIAS SOCIAIS E O TERCEIRO SETOR: UMA ANÁLISE DAS ORGANIZAÇÕES DA ÁREA DA SAÚDE DE SÃO BORJA
}

GRAZIELE LISBOA RODRIGUES UNIASSELVI

SÃO BORJA, RIO GRANDE DO SUL, BRASIL GRAZIELE.LISBOAR@GMAIL.COM

RENATA CORREA COUTINHO UNIVERSIDADE FEDERAL DO PAMPA SÃO BORJA, RIO GRANDE DO SUL, BRASIL RENATACORREACOUTINHO@GMAIL.COM 


\section{MÍDIAS SOCIAIS E O TERCEIRO SETOR: UMA ANÁLISE DAS ORGA- NIZAÇÕES DA ÁREA DA SAÚdE DE SÃO BORJA}

Resumo: Este trabalho tem como objetivo entender o uso das mídias sociais realizado pelas organizações do terceiro setor da área da saúde de São Borja: Grupo de Apoio aos Pacientes Oncológicos de São Borja, Liga Feminina de Combate ao Câncer de São Borja e Sociedade Beneficente Ivan Goulart. Para atender ao objetivo proposto foram realizadas pesquisa bibliográfica, pesquisa exploratória, entrevista em profundidade e análise documental. Palavras-chave: Internet; Terceiro Setor; São Borja.

\section{REDES SOCIALES Y EL TERCER SECTOR: UN ANÁLISIS DE LAS OR- GANIZACIONES DE SALUD EN SÃO BORJA}

Resumen: Este artículo tiene como objectivo comprender el uso de las redes sociales por parte de las organizaciones del tercer sector del área de salud de São Borja: Grupo de Apoyo para Pacientes com cáncer, Liga de cáncer de mujeres de São Borja y Sociedad de beneficencia Ivan Goulart. Para cumplir com el objectivo propuesto se realizo una investigación bibliográfica, investigación exploratoria, entrevista en profundidad y análisis de documentos. Palabras clave: Internet; Tercer sector; São Borja.

\section{SOCIAL MEDIA AND THE THIRD SECTOR: AN ANALYSIS OF HEALTH ORGANIZATIONS IN SÃO BORJA}

Abstract: This paper aims to understand the use of social media by organizations of the third sector of the health area in São Borja: Group Patients Support Cancer, Women's Cancer League and Charity Society Ivan Goulart. In order to meet the proposed objective, a bibliographic research, exploratory research, in-depth interview and document analysis.

Keywords: Internet; Third sector; São Borja.

\section{INTRODUÇÃO}

Diante dos avanços tecnológicos do século XX, a internet surgiu no intuito de satisfazer uma necessidade militar existente na época. Aos poucos, o invento que antes era voltado a um pequeno grupo, expandiu-se no final do mesmo século, atingindo grande parte da população e tornando-se um dos grandes marcos para a sociedade.

Devido aos benefícios e à grande adesão, a internet assumiu novas responsabilidades em meio à sociedade e tornou-se assim, um instrumento voltado não apenas para a informação, mas também para a comunicação. Sua função enquanto meio de comunicação, não se restringe apenas a 
comunicação pessoal, mas engloba também o uso por parte das empresas comerciais e também pelo terceiro setor, que geralmente busca através da rede adquirir visibilidade. Apesar da internet ser um assunto atual, que recebe destaque em produções científicas, a sua utilização em favor do terceiro setor ainda é um tema que recebe pouca atenção e valorização, inclusive por parte da maioria das organizações que nem sempre a utilizam de forma oportuna, de modo a trazer benefícios para a instituição.

Pensando nesse contexto e na realidade da cidade de São Borja, o presente trabalho buscou mapear a presença de algumas organizações sem fins lucrativos nas mídias sociais, para que pudéssemos compreender a importância da internet e os benefícios que a rede pode proporcionar a esse setor que necessita de auxílios para sua manutenção. Considerando a escassa abordagem da temática e a inexistência desses dados em São Borja, foi estabelecido como objeto de estudo as organizações pertencentes à área da saúde do município, sendo elas: Grupo de Apoio aos Pacientes Oncológicos de São Borja (GAPO-SB), Liga Feminina de Combate ao Câncer e a Sociedade Beneficente Ivan Goulart (SBIG).

\section{INTERNET: DO SURGIMENTO DA TECNOLOGIA AO IMPACTO NA SOCIEDADE}

A tecnologia - termo que advém do grego tékhne ${ }^{1}$-, ao contrário de como é tratada hoje pelo senso comum, não é uma invenção do último século e nem se constitui apenas por máquinas eletrônicas. Ela está presente no mundo desde os primórdios, com a descoberta do fogo, e se fortaleceu ainda mais com o avanço da ciência.

O conceito de tecnologia ainda é muito amplo e abordado de diferentes formas, visto que é uma expressão muito antiga, portanto, não se tem muitas definições exatas. Dentre as diversas visões, Castells (1999, p. 67) trata a tecnologia como "o uso de conhecimentos científicos para especificar as vias de se fazerem as coisas de uma maneira reproduzível”. Desse modo, ela não se limita apenas às inovações do século XXI, mas compõe-se de todos os produtos, técnicas e ferramentas que facilitam quaisquer atividades, como por exemplo: o fogo, roda, computadores, softwares, entre outros.

1 Tékhne (técnica) + logia (estudo). Disponível em <https://www.tecmundo.com.br/ tecnologia/42523-o-que-e-tecnologia-.htm> Acesso em 11 Setembro 2017. 
Dentre as criações destacamos o último século devido às constantes invenções que proporcionaram um grande avanço à sociedade, principalmente para a comunicação, que é foco para essa discussão. $O$ final do século XX ficou marcado por uma das maiores transformações tecnológicas: a internet.

Conhecida como uma rede internacional de computadores (SAMPAIO, 2003, p. 302), a internet surgiu em meados da década de 50, durante a Guerra Fria. Em conjunto com a ARPA (Advanced Research Projects Agency), cientistas norte-americanos criaram a tecnologia a fim de suprir uma necessidade militar da época: desenvolver algo que fosse capaz de armazenar e proteger informações sigilosas, e que, ao mesmo tempo servisse como uma ferramenta de comunicação interna dos centros militares. Na época, os dados pertencentes às tropas eram concentrados em um único local, ou seja, qualquer ataque nessa área poderia acarretar na perda total desses materiais. Portanto, a criação de uma rede online que pudesse ser acessada em outros locais se fazia tão necessária como forma de prevenção a um ataque na área central.

Apesar de ser desenvolvida para atender a esse interesse, a internet chamou a atenção dos seus criadores que decidiram expandir a rede para algumas universidades com o propósito de fortalecer o campo de pesquisa (SAMPAIO, 2003). Desse modo, a internet passou a ser um incentivo para o desenvolvimento acadêmico, mas isso só foi possível com o advento da web (World Wide Web-www), em 1991.

Embora sejam distintos, ainda há uma confusão em relação a esses dois termos: internet e web. A internet trata-se de uma rede formada por milhares de computadores do mundo todo e que quando conectados, os usuários têm a possibilidade de se comunicar. Ou seja, é a rede pela qual as informações contidas no computador irão trafegar até chegar ao seu destino final. Já a web é um "modo de organização da informação" dentro da rede (PINHO, 2000, p. 30). Ou seja, diz respeito à parte em que o usuário tem acesso por meio dos navegadores. Para que as pessoas obtenham os serviços, a web não pode funcionar sozinha. Ela depende da rede da internet para se desenvolver e dos navegadores para popularizar os conteúdos através dos conhecidos sites. Os seus conteúdos podem aparecer através de textos, imagens, sons, vídeos, entre outros.

Após ser limitado inicialmente a um pequeno público, o acesso à internet passou a ser comercializado em diversos países, inclusive no Brasil, 
onde a rede foi introduzida em 1995. A inserção da internet no mercado não demorou muito para ser aceita e estabilizada. Atualmente, existem mais de 100 milhões de internautas apenas no Brasil, segundo dados apresentados pela pesquisa TIC Domicílios ${ }^{2}$ do ano de 2015, o que representa aproximadamente $58 \%$ da população brasileira.

Por conta do avanço na sociedade, os criadores da internet viram a possibilidade de aprimorar os serviços disponibilizados dentro da rede de acordo com as necessidades dos usuários. Dentre as diversas atualizações, a internet proporcionou às pessoas a interação e o acesso aos diversos dispositivos. Essas e outras melhorias levaram a web a três fases distintas que são abordadas por alguns autores como: 1.0, 2.0 e 3.0.

De acordo com Silva (2010), a web 1.0 trata-se da fase de implantação da internet no mercado, onde o usuário tinha apenas acesso à informação de forma passiva, de modo que ele não produzia conteúdo dentro da rede. Nesse caso, o seu papel diante da tecnologia era como de um telespectador, ou seja, não havia interação. Martha Gabriel (2010) define essa etapa como "web estática".

A segunda fase (2.0) trata-se de uma web com caráter mais dinâmico e interativo, que permite que o internauta navegue pelos sites, produza conteúdos, exponha o seu ponto de vista acerca de determinado assunto e interaja com pessoas do mundo todo. Ou seja, o conteúdo não é mais produzido e controlado por uma única pessoa responsável pelo site, mas tornou-se uma atividade coletiva. Desse modo, o usuário deixa de ser passivo e passa a ser ativo, não apenas consumindo as informações, mas também contribuindo para a construção delas.

A web 3.0, é conhecida também como semântica, pois preza por dados que são obtidos através das informações disponibilizadas pelo internauta em formulários, nos conteúdos que ele acessa e na localização cedida por ele. Esses elementos servem como referência para que as plataformas ofereçam informações que estejam próximas ao usuário e que sejam de seu interesse. Um exemplo que caracteriza essa fase é a plataforma de busca Google; ao realizar uma pesquisa, o internauta encontrará diversos resultados, sendo que os primeiros serão disponibilizados de acordo com o que ele já acessou e

2 Pesquisa sobre o uso das Tecnologias de Informação e Comunicação, aponta o número de internautas brasileiros. Disponível em <http://www.brasil.gov.br/ciencia-e-tecnologia/2016/og/pesquisa-revela-que-mais-de-100-milhoes-de-brasileiros-acessam-a-internet> Acesso em 28 de Agosto de 2017 
que a plataforma de busca considera mais interessantes para o pesquisador. Através dessa mudança, diminui a exposição do usuário a informações que ele não deseja receber.

As fases da transformação da internet fizeram dela um lugar voltado não apenas para a informação como antigamente, mas também para a comunicação. $O$ aprimoramento da tecnologia tem como principal consequência a mudança do comportamento das pessoas frente à sociedade, o que se tornou tema central para diversos estudos que tratam da Cibercultura.

\section{CIBERCULTURA}

Toda descoberta resulta em algum impacto para a sociedade. As tecnologias não são diferentes e acabam influenciando diretamente o comportamento do internauta. Para que possamos compreender mais sobre o assunto, é necessário conhecer dois termos: ciberespaço e cibercultura.

Pierre Lévy (1999, p. 94) denomina ciberespaço como um "espaço de comunicação aberto que surge pela interconexão mundial dos computadores". Trata-se de um espaço virtual que possibilita a comunicação e o compartilhamento de ideias sem a "necessidade do homem físico". Ou seja, conversar com alguém à distância, sem a necessidade de estar presente, tornou-se possível dentro de um local denominado ciberespaço. É a partir dessa interação que surge o termo cibercultura.

Lévy (1999, p.17) designa a cibercultura como um "conjunto de técnicas, práticas, atitudes, pensamentos e valores que se desenvolvem juntamente com o crescimento do ciberespaço". Ou seja, trata-se de um tipo de cultura que surge a partir da popularização da internet e das novas tecnologias da comunicação. Diferentemente das diversas culturas locais existentes no país, onde cada região possui hábitos, crenças e costumes próprios, a cibercultura é uma cultura popular que se expandiu pelo mundo todo e que foi gerada dentro do ciberespaço.

Hoje é comum utilizar a internet para a realização de diversas ações do cotidiano. Conversar, trocar experiências, pesquisar, pagar e fazer compras, são pequenas ações que antes só eram possíveis de serem executadas no meio off-line e que estão migrando cada vez mais para o meio digital. Torres (2009, p. 44) afirma que devido a esse poder que as pessoas têm dentro da rede, elas "interagem e interferem em toda e qualquer atividade ligada à sociedade e aos negócios". Ou seja, esse novo tipo de cultura decorrente da popularização da internet, acarreta em diversas transformações na socieda- 
de, inclusive sociais e econômicas, devido às atitudes dos usuários no meio.

Um dos pontos afetados que se fortalece no meio online é o crescimento do apoio às causas sociais. As postagens que partem de uma iniciativa individual são repassadas até atingir um grande número de pessoas. Ou seja, é a partir dessas pequenas atitudes que as ações voltadas à essa causa ganham força nas mãos da população.

Diante dessa situação, torna-se evidente a importância da tecnologia para para o avanço da sociedade. É em consequência dessas mudanças e da grande presença das pessoas no ciberespaço que a maioria das organizações e empresas estão aderindo cada vez mais ao meio online em direção ao seu público-alvo. Isso faz da internet não apenas um ponto de encontro entre usuários, mas faz dela também mais uma mídia a ser explorada pela publicidade, no intuito de fortalecer a relação com o seu público.

\section{A NOVA ERA DA COMUNICAÇÃO: A APROPRIAÇÃO DA INTERNET PELA PUBLICIDADE}

Assim como a tecnologia, a publicidade não é uma novidade do último século. É uma prática antiga que era realizada primeiramente através da oralidade e que hoje se mostra presente também nos grandes meios de comunicação.

Pinho (2000, p. 96), define a publicidade como "qualquer forma de apresentar ou promover produtos, serviços e marcas feita por um patrocinador claramente identificado e veiculada nos meios de comunicação". Fazer publicidade é tornar uma informação pública através do uso de meios de comunicação e por meio da criatividade chamar a atenção e convencer quem vê/assiste.

A ação que primeiramente se desenvolvia de forma oral, aos poucos passou a ser realizada também nos meios de comunicação, na medida em que eles surgiam. No Brasil, considera-se oficial o início do investimento em mensagens com tom publicitário no século XIX, momento em que foi veiculado o primeiro anúncio impresso no jornal Gazeta do Rio de Janeiro, constituído apenas por textos (PINHO, 2000). No decorrer dos anos, além de textos foram introduzidas imagens ao anúncio impresso e, posteriormente, imagens em movimento a partir da criação do cinema e anos depois, da televisão. Essas novas linguagens se constituíram devido ao surgimento de novos meios.

Hoje encontramos uma multiplicidade de anúncios quer seja na televi- 
são, no jornal, nas revistas, nas vias públicas, em diferentes locais, públicos e privados. Além disso, a internet tem se tornado um alvo da publicidade para a veiculação de anúncios devido aos benefícios que ela proporciona.

De acordo com Zeff e Aronson (1997, apud PINHO, 2000, p. 119) são cinco benefícios da internet: 1) a dirigibilidade, pois permite que o anunciante conheça os interesses do seu público através de uma breve análise do comportamento do consumidor e direciona as mensagens para o público específico; 2) o rastreamento, que diz respeito ao controle de audiência por meio dos cliques e de ferramentas que proporcionam tal ação; 3) a acessibilidade, pois as mensagens ficam disponíveis para que os consumidores possam acessar a qualquer momento, em vários locais e em diversos suportes (celular, computador, tablet); 4) a flexibilidade, devido à facilidade para colocar e retirar uma campanha de circulação; 5) a interatividade, que permite a participação do público, o que não era possível em outros meios como jornal e televisão. Além dos benefícios citados, a internet tem como principal característica possibilitar que os anunciantes atraiam o público consumidor por um baixo custo, o que tem se tornado cada vez mais frequente através das redes sociais.

Utilizar a internet como uma mídia "não significa criar um site, um blog ou anunciar com banners" (TORRES, 2009, p. 61), mas sim usufruir de forma favorável, investindo em ações que sejam eficazes para a empresa ou organização, de modo que os recursos utilizados não sejam desperdiçados e aplicados em vão. O autor afirma ainda que "incluir a internet como parte de seu planejamento, é fundamental” (TORRES, 2009, p. 61), como forma de evitar falhas e obter mais benefícios dentro de um meio que atinge hoje a maioria da população.

Devido aos seus aspectos positivos, a internet tem sido utilizada não apenas pelas empresas, mas em diversos segmentos da sociedade, inclusive no terceiro setor, no intuito de chamar a atenção do público para a captação de recursos e de novos colaboradores para as suas ações. O uso da internet por esse setor é uma prática que ainda está em fase de crescimento e que se utilizada de forma estratégica, tende a potencializar ainda mais as organizações dentro da sociedade, proporcionando visibilidade e outros benefícios.

\section{TERCEIRO SETOR}

Para uma discussão a respeito do Terceiro Setor é necessária uma breve abordagem acerca dos outros dois setores que o antecedem: o primeiro e o 
segundo setor.

De acordo com Marco Antonio Batan (2004), o primeiro setor diz respeito ao poder público (prefeituras, câmaras, governos, ministérios) que tem como função exercer as questões sociais a eles destinadas. O segundo setor está relacionado ao segmento mercadológico. Estão inseridas nele, todas as empresas privadas que atuam visando o lucro e o seu bem próprio.

A denominação "terceiro setor" se explicaria, para diferenciá-lo do Estado (Primeiro Setor) e do setor privado (Segundo Setor). Ambos não estariam conseguindo responder às demandas sociais: o primeiro, pela ineficiência; o segundo, porque faz parte da sua natureza visar o lucro. Essa lacuna seria assim ocupada por um "terceiro setor" (COUTINHO, 2003, p. 1).

O terceiro setor são as instituições sem fins lucrativos que atuam na sociedade desenvolvendo ações no intuito de satisfazer algumas necessidades dos cidadãos, que caberiam ao Estado suprir, mas que muitas vezes não são atendidas. As instituições do terceiro setor possuem um vasto campo de atuação e podem estar situadas nas diferentes áreas do conhecimento: saúde, educação, meio ambiente, cultura, esportes, lazer (PEREIRA; MUNARETTO; BRUM, 2014, p. 2).

Devido à falta de comprometimento do governo que persiste há muito tempo, a população acaba se mobilizando e se unindo para atender as necessidades de quem precisa. Isso acarreta no aumento significativo do número de organizações do terceiro setor preocupadas com o bem estar da sociedade.

Baseado em um relatório disponibilizado pelo Ministério do Trabalho, "no ano de 1991 existiam mais de 200 mil organizações sem fins lucrativos" (FERNANDES, 2005, p. 28). Há dados mais recentes disponibilizados pela Abong (Associação Brasileira de Organizações Não Governamentais), do ano de $2010^{3}$, que indicam que o número de instituições sem fins lucrativos no país está estimado em uma quantia de 290 mil organizações, as quais são reconhecidas pela Associação Nacional das ONGs.

De acordo com Luiz Carlos Merege (1999 apud PEREIRA, 2010, p. 30), essas organizações "não têm as características de apropriação privada de

3 Pesquisa FASFIL realizada em 2010. Disponível em < http://www.abong.org.br/ ongs.php?id=18> Acesso em 24 Setembro 2017. 
lucros, prestam um serviço público e sobrevivem basicamente da transferência de recursos de terceiros, sejam de famílias, governo ou empresas privadas". Ou seja, por tratarem-se de instituições que não visam lucro, nenhuma organização consegue se manter sozinha, portanto, necessitam do auxílio da comunidade em geral em ações para captação de recursos.

\section{O QUE MANTÉM AS ORGANIZAÇÕES? - PRINCIPAIS MÉTODOS PARA A CAPTAÇÃO DE RECURSOS}

A manutenção de instituições que não visam lucro ainda é um desafio, visto que as organizações dependem de terceiros para permanecerem ativas. A fim de arrecadarem recursos, são diversas as ações que elas realizam na comunidade.

Há algumas organizações, como as não-governamentais (ONGs), que recebem auxílio do governo através de verba pública, porém, para que isso aconteça é necessário que elas sejam formalmente registradas e estejam exercendo as suas atividades há pelo menos três anos, conforme requisitos exigidos pela lei $n^{\circ}$ 9.790. Ou seja, durante os três anos de existência ela deve se manter por conta própria, o que leva muitas organizações a fecharem suas portas.

Como forma de arrecadar recursos materiais e financeiros, as organizações utilizam de estratégias - conhecidas também como fundraising ( $M O N$ TAÑO, 2007, p. 207) - para atingir as pessoas e para incentivar a realização de doações. Essas ações além de possibilitarem um auxílio financeiro, chamam a atenção da população e atraem novos colaboradores/voluntários.

No terceiro setor, são diversas as formas de arrecadar fundos. Entre as mais frequentes estão a realização de cafés coloniais, jantares, bingos e brechós, porém, essas ações são voltadas apenas ao público local, de modo que as organizações não conseguem atingir os públicos das demais regiões. No intuito de expandir suas ações, a utilização da internet é uma prática que tem fortalecido esse setor, principalmente nas grandes cidades, e que tem levado as organizações às áreas que elas não conseguiriam alcançar com os meios de comunicação tradicionais.

Na web são desenvolvidas diversas ações, como no Facebook, onde o número de compartilhamentos e check-ins nas empresas parceiras são revertidos em um determinado valor que é doado para as organizações. Além disso, outro exemplo de ação digital é aquela em que os usuários têm a chance de ajudar as instituições através do consumo de materiais personalizados 
(canecas, agendas, calendários, camisetas, bottons, etc.) que são vendidos pelas organizações nas redes sociais e nos sites.

Outra prática explorada por esse setor é o crowdfunding, conhecido também como financiamento coletivo online. O termo foi criado segundo Reeberg (2016) em 2006 e consiste na contribuição de diversas pessoas a fim de um único objetivo: financiar determinado projeto social. A ação é realizada na internet através de diversas plataformas, sendo a maior delas o site Catarse.me, onde a população pode ajudar diversas causas que necessitam de recursos financeiros. Ela tem as mesmas características de uma "vaquinha" online, porém, ela não dá retorno para uma pessoa específica, mas sim para toda a sociedade. Esse método tem sido muito utilizado pelas organizações devido a sua abrangência que alcança pessoas de todas as regiões.

De acordo com Marco Antonio Batan (2004, p. 51), a web permite que as organizações conquistem "recursos, trabalho voluntário, parceiros e boa vontade do público e dos políticos para que a sociedade procure atenuar problemas sociais", de modo que não são gerados custos, ou seja, quando utilizada de forma estratégica, a internet pode ser utilizada para atingir um grande público de forma gratuita.

Como as organizações dispõem de poucos recursos financeiros, o que elas recebem é voltado para a compra de mantimentos, nesse caso, o investimento em publicidade não é uma prioridade para elas, ainda que algumas utilizem. Porém, a falta de comunicação acaba tornando-se um problema para muitas instituições. Divulgar é a principal coisa a ser feita para se atingir um público, pois é através da divulgação que as organizações passam a ter mais visibilidade, podendo assim, despertar o interesse no público para que eles ajudem, seja através de doações ou do próprio voluntariado. Dessa forma, as que não se comunicam pouco atingem o seu público e consequentemente, não têm os mesmos benefícios que as demais.

Apesar da web possibilitar melhores resultados para o terceiro setor, são poucas as instituições que usufruem dos serviços disponibilizados, porém, não há um estudo concreto que apresente resultados sobre esse investimento, principalmente na cidade de São Borja que é alvo para essa pesquisa.

\section{CENÁRIO DO TERCEIRO SETOR EM SÃO BORJA}

Fundada em 1682, a cidade de São Borja está localizada no oeste do estado do Rio Grande do Sul e é composta por uma população de 61.671 habi- 
tantes, segundo o censo do IBGE (2010), sendo que a maioria, 51\%, são muIheres. O município é conhecido também por ser a "Terra dos Presidentes", onde nasceu Getúlio Vargas e João Goulart.

Por estar localizada na região dos Pampas, onde se tem grandes áreas de campos, a principal fonte de renda do município provém da agricultura. Além disso, outra fonte de renda é o comércio constituído principalmente por empresas locais, que oferecem emprego a diversos são-borjenses.

A maioria das empresas comerciais dispõem de pouco investimento em publicidade, o que acarreta a falta de visibilidade. Isso ocorre também com as demais organizações do município, inclusive com aquelas que dependem do apoio da população: as instituições do terceiro setor. Essa falta de divulgação é um fator que dificulta qualquer ajuda ou doação, e até mesmo estudos, devido ao desconhecimento que há em relação a essas organizações.

Nesse sentido, a fim de entender o uso das mídias sociais pelo terceiro setor de São Borja, o presente estudo tem como base uma pesquisa exploratória ${ }^{4}$ desenvolvida pela autora, que apontou a existência de 44 instituições, as quais foram classificadas em 16 áreas de atuação. Conforme os dados apresentados pela pesquisa, foi definido como objeto de estudo as organizações pertencentes à área da saúde: Grupo de Apoio aos Pacientes Oncológicos (GAPO-SB); Liga Feminina de Combate ao Câncer; Sociedade Beneficente Ivan Goulart (SBIG), a fim de perceber a importância da internet e a sua contribuição para o setor. Optou-se trabalhar com essa parcela, pois trata-se de uma área básica da sociedade que deveria receber mais atenção, mas que ainda se encontra em um cenário pouco favorável devido a carência de investimentos por parte do Estado. Desse modo, crescem as ações para fortalecer esse setor, inclusive no meio online.

Portanto, a fim de entender a importância das mídias sociais e compreender o uso que cada organização faz desse meio, o estudo se baseia em quatro métodos: pesquisa bibliográfica, em torno de autores que tratam do assunto; pesquisa exploratória a fim de mapear o cenário das organizações em São Borja; entrevista em profundidade, guiada por meio de um questionário semi-estruturado e realizada com um representante de cada organização selecionada; análise documental nas redes sociais (Facebook e

4 Realizada no Cartório Civil de São Borja, a fim de descobrir o número de organizações existentes no município. Desenvolvida no decorrer do mês de Abril de 2017, para o Trabalho de Conclusão de Curso. 
Instagram) e nos demais sites utilizados pelas organizações. Como recorte para este artigo, foram apresentados apenas os resultados ${ }^{5}$ gerais obtidos.

\section{RESULTADOS OBTIDOS NO ESTUDO}

Diante dos dados obtidos, observou-se que apesar de atuarem na mesma área do terceiro setor, há uma discrepância em relação ao uso que as três organizações fazem da mídia social.

A primeira organização analisada (GAPO-SB) está presente na internet através do Facebook e Instagram, porém, não são utilizados com a intenção de divulgar as suas ações. Segundo a voluntária entrevistada, a finalidade do GAPO-SB é transmitir dicas à população que necessita de informações para a prevenção do câncer. Das três instituições investigadas, essa é a que mais realiza publicações. Porém, a quantidade não é um fator que proporciona benefícios, pelo fato de que a maioria das publicações são mensagens com frases positivas compartilhadas de terceiros.

A fanpage e o perfil privado no Instagram do GAPO-SB (fato que dispersa os seguidores) são gerenciados pelos próprios voluntários sem a presença de um planejamento, ou seja, toda e qualquer publicação é realizada de forma aleatória, exceto quando uma funcionária do hospital auxilia na divulgação e produção de conteúdo. Com isso, pouco atraem voluntários e não captam recursos através da internet. Segundo a entrevistada, o GAPO-SB obteve poucos benefícios com o uso da ferramenta, porém, é um fato que se dá através do pouco investimento no meio.

A Liga Feminina de Combate ao Câncer de São Borja, segunda instituição analisada, está ativa na internet desde 2017, porém, investe no meio de forma mais estratégica. Com o auxílio de uma voluntária especializada na área da Comunicação, utiliza as plataformas como forma de informar e de divulgar o trabalho executado, a fim de atrair a comunidade para os eventos. Como forma de arrecadar recursos comercializam camisetas, realizam sorteios e eventos que são divulgados nas plataformas. Como retorno desse investimento, os eventos da Liga Feminina obtiveram mais visibilidade, fato comprovado pela presidente da associação.

A última organização investigada, a Sociedade Beneficente Ivan Gou-

5 Para acessar os dados na íntegra: http://dspace.unipampa.edu.br/bitstream/ riu/2555/1/Graziele\%20Lisboa\%20Rodrigues\%20\%282017\%29.pdf 
lart, embora considere a internet o principal meio de comunicação existente hoje para se atingir um grande público, não possui uma página própria com conteúdo que atende exclusivamente as suas atividades, apenas divulga as suas ações através do site do Hospital Ivan Goulart e outros de notícias. A ausência no meio online tem como consequência a carência de dados a respeito da instituição e pode acarretar também no desconhecimento de parte da população que está presente no meio e que o utiliza para obter informações.

A partir da análise realizada, entende-se que embora duas organizações considerem a internet um meio importante a ser explorado, apenas uma das instituições (Liga Feminina de Combate ao Câncer) a utiliza de forma proveitosa, de modo a promover os seus serviços, obter apoio da comunidade nas ações realizadas e captar recursos necessários para se manter. Essa é uma prática que só se concretizou com a chegada de uma voluntária que em conjunto com a presidente da instituição, constatou a necessidade de investir em um meio que permita um grande alcance de público de forma gratuita. Com o auxílio da voluntária profissional de comunicação, a qual planeja as ações antes de qualquer veiculação, foi comprovado que apenas a presença nestas plataformas e as inúmeras publicações informativas não são suficientes para que uma organização adquira benefícios. Dessa forma, entende-se que embora as organizações possuam outras prioridades, a publicidade e o investimento na internet de forma planejada não devem ser deixados de lado, visto que podem proporcionar benefícios essenciais para que uma instituição prossiga o seu trabalho em prol da comunidade.

\section{CONSIDERAÇÕES FINAIS}

Conforme discutido no decorrer deste trabalho, percebe-se que a tecnologia foi um fator fundamental para a evolução da sociedade, contribuindo nos diversos segmentos que nos cercam: saúde, comunicação, informática, transporte, entre outros. Embora o termo tecnologia seja muito amplo, ele se caracteriza pelas inúmeras invenções criadas para facilitar a vida da população, dentre elas está a internet, a qual surgiu para suprir uma determinada necessidade militar, e que, com o tempo tornou-se um dos principais meios de comunicação utilizados pelas empresas e organizações do terceiro setor como forma de atingirem os seus públicos.

O uso da internet pelo terceiro setor, o qual é representado pelas organizações sem fins lucrativos, sempre foi um interesse pessoal e se intensificou 
após a constatação da carência de estudos referentes a esses dois pontos. Pensando nessa temática, surgiu a necessidade de entender como essas organizações utilizam esse meio, se elas estão presentes na mídia digital, para que elas utilizam, se as ações realizadas online proporcionam benefícios ou se elas simplesmente não atuam na internet.

Diante das três organizações definidas como objeto de estudo: GAPO-SB, Liga Feminina e SBIG, foi constatado que todas estão presentes na mídia digital mas a utilizam de maneira distinta, sendo que duas delas possuem a intenção de divulgar suas ações e outra de transmitir informações referentes à saúde. Além disso, outra característica que as difere é que apenas uma organização possui uma profissional da área da Comunicação para a produção de conteúdo planejado, o que permitiu que a instituição se destacasse e obtivesse mais benefícios financeiros e visibilidade em relação às demais. Com isso, podemos perceber a importância de um profissional publicitário dentro de qualquer empresa ou organização. Independente do ramo em que atua, é fundamental pensar estrategicamente para alcançar da melhor forma o público desejado e se destacar, principalmente no meio online onde a concorrência está cada vez maior.

A partir das informações analisadas, entende-se que a internet exerce uma função importante não apenas para o relacionamento entre as pessoas, mas exerce o papel de potencializadora das causas sociais, proporcionando diversos benefícios por um baixo custo. A internet pode ser na maioria das vezes mais eficaz e oportuna que outros meios, porém deve ser utilizada de forma planejada com o auxílio de pessoas que saibam fazer o uso estratégico do meio para que essas ações não sejam aplicadas em vão.

\section{REFERÊNCIAS}

BATAN, Marco A. Propaganda no terceiro setor. Santos: Editora Universitária Leopoldianum, 2004.

CASTELLS, Manuel. A sociedade em rede. p. 67-71. São Paulo: Paz e Terra, 1999.

COUTINHO, Joana. Desmistificando o Terceiro Setor. 2003. Disponível em: <https://revistas.pucsp.br/index.php/ls/article/view/25783/18427> Acesso em 17 Novembro 2017.

GABRIEL, Martha. Marketing digital. In: Marketing na Era digital. São Paulo: Novatec Editora, 2010.

LÉVY, Pierre. Cibercultura. São Paulo: Editora 34, 1999.

MONTAÑO, Carlos. Terceiro setor e questão social: crítica ao padrão emergente de intervenção social. 4ed. São Paulo: Cortez, 2007, p. 195-210. 
PEREIRA, João; MUNARETTO, Lorimar; BRUM, Tônia; Inovações na gestão de pessoas em organizações do terceiro setor: o caso de uma sociedade espírita com assistência socioeducacional. In: III SINGEP e II S2IS, 2014, São Paulo. Disponível em <https://singep.org. br/3singep/resultado/402.pdf> Acesso em 25 Agosto 2017.

PINHO, José B. Publicidade e vendas na internet: Técnicas e Estratégias. São Paulo: Summus, 2000.

SAMPAIO, Rafael. Propaganda de A a Z. 3ed. Rio de Janeiro: Elsevier, 2003.

TORRES, Cláudio. A Bíblia do marketing digital: tudo o que você queria saber sobre marketing e publicidade na Internet e não tinha a quem perguntar. São Paulo: Novatec Editora, 2009. 


\section{Graziele Lisboa Rodrigues}

Graduada em Comunicação Social habilitação em Publicidade Propaganda pela Universidade Federal do Pampa, campus São Borja, RS. Pós-graduanda em Marketing Digital pela Uniasselvi.

E-mail: graziele.lisboar@gmail.com

\section{Renata Correa Coutinho}

Professora adjunta da Universidade Federal do Pampa, (UNIPAMPA, campus São Borja, RS), do Curso de Publicidade e Propaganda e do Mestrado Profissional em Comunicação e Indústria Criativa. E-mail: renatacorreacoutinho@gmail.com E-mail: renatacorreacoutinho@gmail.com 